\title{
UMA ANÁLISE DA PERCEPÇÃO E SATISFAÇÃO DOS USUÁRIOS QUANTO AO SERVIÇO PRESTADO POR UMA COMPANHIA DE TRANSPORTE AÉREO DOMÉSTICO
}

\author{
Valdecir Cahoni Rodrigues, Alvaro Costa Jardim Neto, Giovani Pereira Silva, Alana Karine Santos \\ Universidade do Oeste Paulista - UNOESTE, Curso de Administração, Presidente Prudente, SP. E-mail: \\ cahoni@unoeste.br
}

\section{RESUMO}

Esta pesquisa buscou analisar a percepção dos usuários quanto ao serviço de prestação de serviços prestado por uma companhia de transporte aéreos domésticos e a estrutura aeroportuária da cidade de Presidente Prudente/SP. O método utilizado foi um estudo bibliográfico com pesquisas em fontes primárias e secundárias analisando os principais autores que abordam sobre o tema e por fim um estudo de caso acompanhado de um estudo de campo. Por intermédio da pesquisa concluiu-se que os usuários se encontram entre satisfeitos e muito satisfeitos quanto ao serviço prestado pela companhia aérea, mas quanto a estrutura aeroportuária os mesmos encontram-se insatisfeitos. Como sugestão para futuras pesquisas seria importante realizar uma análise cujo objetivo seria detectar os motivos que levam os demais indivíduos a utilizarem os serviços aéreos da empresa concorrente e não da empresa objeto da pesquisa.

Palavras-chave: Companhias Aéreas; Satisfação; Percepção.

\section{AN ANALYSIS OF THE PERCEPTION AND SATISFACTION OF USERS FOR THE SERVICE PROVIDED BY A COMPANY OF DOMESTIC AIR TRANSPORT}

\begin{abstract}
This research sought to analyze the users' perception of the service rendered by a domestic air transport company and the airport structure of the city of Presidente Prudente / SP. The method used was a bibliographic study with researches in primary and secondary sources analyzing the main authors that approach on the subject and finally a case study. Through the research it was concluded that the users are between satisfied and very satisfied about the service provided by the airline, but as for the airport structure they are dissatisfied. As a suggestion for future research, it would be important to carry out an analysis whose objective would be to detect the reasons that lead the other individuals to use the airline services of the competing company and not the company object of the research.
\end{abstract}

Keywords: Airlines; Satisfaction; Perception.

\section{INTRODUÇÃO}

Em prestação de serviços a satisfação do usuário está relacionada com a qualidade dos serviços que são ofertados e prestados. Mas falar de qualidade em serviços não é nada fácil visto que tem como característica ser intangível, ou seja, não podem ser vistos ou tocados. Estas características dificultam a percepção de qualidade por parte dos usuários e até mesmo pelas próprias empresas prestadoras de serviços.

As empresas aéreas buscam cada dia mais ampliar a sua penetração no mercado a procura de novos clientes e procura manter maior número possível destes clientes fidelizados a sua companhia pelo maior prazo possível sem que leve em consideração somente o preço, mas também outros atributos que estão envolvidos neste tipo de serviço. No Brasil as Companhias áreas domésticas mais conhecidas e ainda concorrentes entre si são empresas como a Azul, Gol, Passaredo e Latam onde a ANAC (Agência nacional de aviação Civil) possibilita acesso a várias informações tais como pontualidade, informações sobre atrasos e cancelamentos e bagagens extraviadas e danificadas. Desta maneira o próprio consumidor tem condições de 
verificar qual companhia ele se sente mais confortável em utilizar. A procura pela melhoria contínua da prestação de serviço destas empresas têm sido constante e principalmente a empresa Azul objeto desta pesquisa que está sempre preocupada em analisar como os seus consumidores veem a qualidade de seus serviços prestados, detectando o que precisa ser melhorado ou mudado e ainda analisando as principais mudanças necessárias para melhoria de seu próprio sistema organizacional.

Com este propósito esta pesquisa tem como objetivo geral identificar e analisar a percepção e a satisfação dos usuários quanto ao serviço prestado pela companhia de transporte aéreo doméstico e ainda a estrutura aeroportuária da cidade de Presidente Prudente/SP.

Como problema esta pesquisa procura responder ao seguinte questionamento: Qual a percepção e a satisfação dos usuários quanto ao serviço prestado pela companhia e sua estrutura portuária na cidade de Presidente Prudente/SP?

A hipótese é de que os clientes estão satisfeitos com os serviços prestados pela companhia aérea, mas procuram melhorias em função da estrutura aeroportuárias oferecida. Justifica-se esta pesquisa porque a partir dos resultados alcançados os gestores da companhia terão condições de tomar medidas quanto aos resultados.

Para atingir este objetivo geral foram propostos os seguintes objetivos específicos:

- Realizar uma pesquisa exploratória para

que $o$ pesquisador possa ampliar o seu conhecimento sobre o tema abordado;

-Realizar uma pesquisa bibliográfica analisando os principais autores que tratam sobre o assunto abordado;

-Analisar o nível de satisfação dos consumidores que utilizam a companhia aérea e ainda detectar as novas necessidades.

- Analisar o nível de satisfação oferecido pela estrutura aeroportuária na cidade de Presidente Prudente/SP

\section{MÉTODOS}

Para alcançar os objetivos propostos nesta pesquisa foi utilizado uma pesquisa bibliográfica com o objetivo de agregar mais conhecimento sobre o assunto abordado para que desta maneira acrescentasse mais valor ao resultado da pesquisa. A pesquisa bibliográfica segundo Manzo (1971, p.32) "oferece meios para definir, resolver, não somente problemas já conhecidos, como também explorar novas áreas onde os problemas não se cristalizaram suficientemente".

Um segundo passo foi a utilização da pesquisa de campo junto aos usuários dos serviços prestados pela empresa objeto de estudo cujo objetivo foi conhecer a percepção e a satisfação dos usuários quanto aos serviços prestado pela empresa e a estrutura aeroportuária da cidade de Presidente Prudente/SP. Segundo Marconi e Lakatos (2005, p.188) “Pesquisa de campo é aquela utilizada com o objetivo de conseguir informações e/ou conhecimento acerca de um problema, para o qual se procura uma resposta, ou de uma hipótese, que se queira comprovar [...]"

Para este levantamento de dados foi aplicado um questionário com perguntas fechadas sendo que a maioria das perguntas a serem respondidas foi estabelecido uma escala de 1 a 5 sendo que quanto menor o valor você "discorda totalmente" e maior o valor você "concorda totalmente". Este tipo de escala é conhecido como escala de Likert que teve como objetivo medir o grau de satisfação dos usuários.

Quanto a técnica de coleta de dados primários, a amostragem se constituiu de maneira não-probabilística intencional, sendo abordados 106 usuários que responderam ao questionário. Os usuários em questão eram de quatro horários diferentes, cinco horas e vinte minutos com destino a cidade de Campinas/SP, onze horas e quinze minutos com destino a cidade de Campinas, quatorze horas e cinco minutos com destino a cidade de Porto Seguro/BA e dezenove horas e trinta e cinco minutos com destino para Campinas.

Como caracterização da empresa objeto de estudo, a Azul Linhas Aérea é a companhia que mais cresceu no Brasil desde que iniciou suas operações em dezembro de 2008, contando atualmente com a maior malha aérea do país atendendo mais de 100 destinos com 864 decolagens diárias. Além disso, recentemente expandiu as operações com voos diretos para os Estados Unidos.

Hoje, com aproximadamente um terço do mercado brasileiro de aviação civil em termos de decolagens, a Azul consolida-se como a terceira maior companhia aérea do País. A clara visão de negócio, traduzida no contínuo crescimento de sua frota, malha de destinos, linhas operadas e participação de mercado, faz da Azul uma 
realidade de notável sucesso. Neste período, a empresa atingiu recordes mundiais e conquistou alguns dos melhores índices do setor de aviação brasileira. O papel da Azul é estimular o tráfego aéreo e dinamizar a economia brasileira por meio de uma equação tão simples de entender quanto difícil de imitar: preços baixos com alta qualidade de serviços.

A qualidade de seus serviços já foi por inúmeros prêmios, nacional e internacional. Em 2015 foi eleita pela quinta vez consecutiva pela Skytrax World AirlineAwards como "Melhor companhia aérea low-cost da América do Sul". Em 2015, a Azul também foi a companhia aérea low-cost mais pontual do mundo de acordo com a OAG. (www.voeazul.com.br)

\section{RESULTADOS}

Foi aplicado um total de 106 questionários em 4 voos em horários diferentes no aeroporto de Presidente Prudente, com o objetivo de identificar e analisar a percepção e a satisfação dos usuários quanto ao serviço prestado pela companhia de transporte aéreo doméstico e ainda a estrutura aeroportuária da cidade de Presidente Prudente/SP.

Dos entrevistados $58,5 \%$ são do sexo masculino e $41,5 \%$ feminino. Quando questionados quantas vezes eles utilizavam a companhia, $2,8 \%$ desse total viaja diariamente, $23,6 \%$ viaja semanalmente, $32,1 \%$ viaja mensalmente, $31,1 \%$ viaja anualmente, e $10,4 \%$ viajam esporadicamente. Nota-se que mais de $58 \%$ dos usuários utilizam sempre a empresa mensamente e na maioria das vezes por questões de trabalho em outros centros. Já os demais utilizam por questões de férias, etc.

Ao serem questionados sobre a escolha da companhia aérea $54,7 \%$ escolhe a empresa por ofertar o menor preço quando comparada com a concorrente, $24,5 \%$ responderam que escolhem pelo atendimento, 4,7\% justificaram que á a única opção que eles têm, 13,2\% escolheu por indicação de amigos ou parentes e $2,8 \%$ por outros motivos. Este resultado mostra que o diferencial competitivo da empresa está no quesito preço $A$ questão do atendimento que julgava-se importante por parte da empresa ficou em segundo lugar na percepção dos usuários.

Quando questionados sobre qual meio mais utilizavam para a realização da compra, $11,3 \%$ dos entrevistados preferem comprar a sua passagem pelo guichê da empresa, $43,4 \%$ compram utilizando o site, $8,5 \%$ compram pelo aplicativo de celular e $36,8 \%$ compram em agências de viagem. Nota-se que a maioria dos usuários adquirem suas passagens aéreas pelo próprio site da companhia. Isso mostra que os usuários procuram facilidade e comodidade na hora de realizar a aquisição de suas passagens.

Para as demais questões os usuários utilizaram uma escala de 1 a 5 para darem nota, sendo que quanto menor o valor você "discorda totalmente" e maior o valor você "concorda totalmente".

Quanto ao questionamento se no site o cliente encontrar o que ele procura, $1,9 \%$ dos entrevistados deram a nota $2,13,2 \%$ deram nota $3,52,8 \%$ deram nota 4, 30,2\% deram nota 5 e $1,9 \%$ não responderam a questão. Nota-se que mais de $8 \%$ deram notas entre 4 e 5 o que significa que eles estão satisfeitos com o site da empresa. Este é um fator importante já que a maioria dos usuários compram suas passagens utilizando o site ou o aplicativo pelo celular.

Quando questionados se o site facilitava completar a transação rapidamente, $2,8 \%$ dos entrevistados deram nota $2,23,6 \%$ deram nota 3 , $45,3 \%$ deram nota $4,26,4 \%$ deram nota 5 e $1,9 \%$ não responderam. A maioria encontra-se também satisfeitos com este quesito.

Quando questionados se as informações no site são bem organizadas, $0,9 \%$ deram a nota $1,4,7 \%$ deram nota $2,27,4 \%$ deram nota $3,45,3 \%$ deram nota 4, 20,8 deram nota 5 e 0,9 não responderam. Nota-se que a maioria se encontra muitos satisfeitos.

Quando questionados se as páginas do site carregam facilmente, $0,9 \%$ deram nota 1 , $5,7 \%$ deram nota $2,33 \%$ deram 3,33\% deram nota 4, 26,4\% deram nota 5 e 0,9 não responderam. Os dados mostram que a maioria se encontram satisfeitos. Levando em consideração que a maioria prefere o site ou o aplicativo para adquirirem suas passagens a empresa deverá investir mais no site.

Questionados se o site auxilia o usuário a navegar dentro dele de forma rápida, $0,9 \%$ deram nota $1,9,4 \%$ deram nota $2,21,7 \%$ deram nota 3 , $38,7 \%$ deram nota 4 e $27,4 \%$ deram nota 5 e 1,9 não responderam. Novamente os clientes encontram-se entre parcialmente e totalmente satisfeito.

Questionados se o site se encontra sempre disponível, 7,5\% deram nota 2, 22,6\% deram nota 3, $41,5 \%$ deram nota 4 e $27,4 \%$ deram nota 5 e 0,9 não responderam, o que indica que a maioria dos clientes encontram-se 
parcialmente satisfeito. A empresa vem investindo continuamente em seu site, pois sabe que é um dos melhores meios de manter relacionamento com os seus usuários.

Quando questionados sobre a emissão do cartão de embarque pelo aplicativo, 0,9\% deram nota $1,2,8 \%$ deram nota $2,32,1 \%$ atribuíram nota $3,32,1 \%$ deram nota 4 e $28,1 \%$ deram nota 5 e 3,8\% não responderam.

Em relação ao horário de serviços extras (ônibus, parcerias); 3,8\% dos entrevistados deram nota $2,16 \%$ deram nota $3,43,4 \%$ deram nota 4, 33\% deram nota 5 e 3,8\% não responderam. Nota-se que a maioria dos entrevistados deram nota entre 4 e 5 o que mostra que os mesmos se encontram satisfeitos com o serviço prestado.

Quanto ao programa de fidelidade abordado pela empresa, $2,8 \%$ deram nota $1,3,8 \%$ deram nota $2,15,1 \%$ deram nota $3,35,8 \%$ deram nota 4 e $36,8 \%$ deram nota 5 . Dos entrevistados $5,7 \%$ não responderam. Novamente a maioria dos clientes encontram-se parcialmente satisfeitos. Neste quesito a empresa pode investir mais para que um número maior de usuários sintam-se satisfeitos.

Referente ao valor de excesso de bagagem, 7,5\% deram nota $1,21,7 \%$ deram nota $2,34 \%$ deram nota 3, 19,8\% deram nota $4,11,3 \%$ deram nota 5 e 5,7\% não responderam.

Quando os clientes foram questionados sobre o chat de tirar dúvidas, $2,8 \%$ deram nota 2 , $29,2 \%$ deram nota $3,36,8 \%$ deram nota $4,26,4 \%$ deram nota 5 e 4,7 não responderam.

Referente ao cancelamento de passagem, $0,9 \%$ deram nota $1,13,2 \%$ deram nota $2,41,5 \%$ deram nota $3,26,4 \%$ deram nota $4,14,2 \%$ deram nota $5,3,7 \%$ não responderam. Neste sentido a empresa necessita melhorar o seu atendimento, pois mais da metade dos usuários pesquisados estão insatisfeitos com esta prestação de serviço.

Quanto a aparência dos funcionários, $0,9 \%$ deram nota $2,11,3 \%$ deram nota $3,37,7 \%$ deram nota 4, 48,1\% deram nota 5 e 1,9\% não responderam. Os dados mostram os clientes estão entre parcialmente e totalmente satisfeitos com a aparência dos funcionários da empresa.

Quanto a cortesia dos funcionários, $21,7 \%$ deram nota $3,43,4 \%$ deram nota $4,33 \%$ deram nota 5 e 1,9\% não responderam. Neste quesito o resultado é satisfatório.

Quando questionados sobre a boa vontade do funcionário da companhia em resolver problemas inesperados, 1,9\% deram nota $2,18,9 \%$ deram nota $3,43,4 \%$ deram nota 4 , $34 \%$ deram nota 5 e 1,9\% não responderam. 0 resultado mostra que a maioria dos clientes se encontram entre parcialmente e totalmente satisfeito.

Quanto a rapidez na solução de problemas e esclarecimento de dúvidas, 1,9\% deram nota $2,24,5 \%$ deram nota $3,40,6 \%$ deram nota 4, 30,2\% deram nota 5 e 2,8 não responderam. Já sobre a solução e esclarecimento de dúvidas via telefone 0,9\% deram nota $1,4,7 \%$ deram nota $2,22,6 \%$ deram nota $3,34,9 \%$ deram nota $4,31,1 \%$ deram nota 5 e $5,7 \%$ não responderam.

Quando questionados sobre a estrutura da aeronave, se a mesma tem uma aparência moderna $0,9 \%$ deram nota $2,8,5 \%$ deram nota 3 , $37,7 \%$ deram nota $4,48,1 \%$ deram nota 5 e 4,7\% não responderam, mostrando que mais da metade dos usuários questionados estão satisfeitos com a aparência da aeronave da companhia.

Quanto ao atendimento das comissárias de voo $10,4 \%$ deram nota $3 ; 38,7 \%$ deram nota 4 , $47,2 \%$ deram nota 5 e 3,8\% não responderam, mostrando que os clientes se encontram parcialmente ou totalmente satisfeitos com os serviços prestados pelas mesmas.

Quando questionados sobre a alimentação dentro da aeronave $11,3 \%$ deram nota $2,15,1 \%$ deram nota $3,35,8 \%$ deram nota 4 , $34,9 \%$ deram nota 5 e 2,8\% não responderam.

Sobre as informações prestadas por parte do piloto $17,9 \%$ deram nota $3,36,8 \%$ deram nota 4, 42,5\% deram nota 5 e 2,8\% não responderam. Neste quesito mostra-se que os usuários estão também satisfeitos.

Perante a rapidez no embarque e desembarque $1,9 \%$ deram nota $2,13,2 \%$ deram nota $3,41,5 \%$ deram nota $4,40,6 \%$ deram nota 5 e 2,8\% não responderam.

Sobre a companhia cumprir os horários fornecidos 1,9\% deram nota 2, 13,2\% deram nota 3, 36,8\% deram nota 4, 45,3\% deram nota 5 e $2,8 \%$ não responderam, mostrando satisfação por parte dos clientes referente aos horários fornecidos.

Quando questionados sobre a limpeza das aeronaves $0,9 \%$ deram nota $2,9,4 \%$ deram nota 3, 39,6\% deram nota 4, 47,2\% deram nota 5 e $2,8 \%$ não responderam, mostrando que a maioria dos clientes encontram-se satisfeitos com a limpeza prestada nas aeronaves. 
Questionados sobre os assentos das aeronaves se são confortáveis $2,8 \%$ deram nota $2,9,4 \%$ deram nota $3,49,1 \%$ deram nota $4,35,8 \%$ deram nota 5 e $2,8 \%$ não responderam. 0 resultado mostra que os usuários estão satisfeitos com os assentos.

Referente ao tempo de conexão 0,9\% deram nota $1,7,5 \%$ deram nota $2,19,8 \%$ deram nota 3, 34\% deram nota $4,34,9 \%$ deram nota 5 e $2,8 \%$ não responderam.

Foram questionados também sobre a estrutura aeroportuária da cidade de Presidente Prudente e quando foi perguntado sobre a localização do aeroporto, se é de fácil acesso $3,8 \%$ deram nota $1,20,8 \%$ deram nota $2,39,6 \%$ deram nota $3,25,5 \%$ deram nota $4,8,5 \%$ deram nota 5 e 1,9\% não responderam. 0 resultado mostra que os clientes se encontram parcialmente insatisfeitos e parcialmente satisfeitos.

Quanto ao valor do estacionamento 0,9\% deram nota $1,36,8 \%$ deram nota $2,45,3 \%$ deram nota $3,9,4 \%$ deram nota $4,3,8 \%$ deram nota 5 e $3,8 \%$ não responderam, mostrando que a maioria dos clientes encontram-se parcialmente insatisfeito. A maioria dos usuários acreditam que o valor cobrado pelo estacionamento seja elevado.

Questionados sobre os banheiros do aeroporto, $5,7 \%$ deram nota $1,44,7 \%$ deram nota $2,18,9 \%$ deram nota $3,17,9 \%$ deram nota $4,2,8 \%$ deram nota $5,10,4 \%$ não responderam. Os dados mostram que os usuários estão insatisfeitos com o quesito banheiro.

Referente a praça de alimentação $43,4 \%$ deram nota $1,19,8 \%$ deram nota $2,16 \%$ deram nota $3,8,5 \%$ deram nota $4,2,8 \%$ deram nota $5,9,4 \%$ não responderam. A maioria dos clientes encontram-se insatisfeitos com a estrutura da praça de alimentação, mostrando assim a necessidade de melhoria neste quesito.

Quanto as placas indicativas 6,6\% deram nota $1,30,2 \%$ deram nota $2,34 \%$ deram nota 3 , $17,9 \%$ deram nota $4,4,7 \%$ deram nota $5,12,3 \%$ não responderam. A maioria está entre totalmente insatisfeito e parcialmente insatisfeito, mostrando que as placas indicativas precisam ser melhoradas, e que os clientes sentem falta de mais informações.

Sobre as informações em geral 1,9\% deram nota $1,20,8 \%$ deram nota $2,42,5 \%$ deram nota $3,22,6 \%$ deram nota $4,9,4 \%$ deram nota 5 e $2,8 \%$ não responderam, indicando que a maioria dos clientes encontram-se parcialmente satisfeitos com as informações prestadas pela companhia na estrutura do aeroporto.

Sobre o balcão da empresa $0,9 \%$ deram nota $1,5,7 \%$ deram nota $2,38,7 \%$ deram nota 3 , $40,6 \%$ deram nota $4,11,3 \%$ deram nota 5 e $2,8 \%$ não responderam, mostrando que eles se encontram parcialmente satisfeitos com a estrutura da companhia.

Quando questionados sobre a sala de embarque $1,9 \%$ deram nota $1,13,2 \%$ deram nota $2,32,1 \%$ deram nota $3,35,8 \%$ deram nota 4 , $15,1 \%$ deram nota $5,2,8 \%$ não responderam. Os resultados mostram que os usuários se encontram parcialmente satisfeitos.

Questionados se os clientes acham que o aeroporto oferece um ambiente agradável 2,8\% deram nota $1,13,2 \%$ deram nota $2,42,5 \%$ deram nota $3,32,1 \%$ deram nota $4,6,6 \%$ deram nota 5 e $3,7 \%$ não responderam.

Quando questionados sobre o Wifi no aeroporto $4,7 \%$ deram nota $1,1,9 \%$ deram nota 2, $0,9 \%$ deram nota 3,4 e $5.90,5 \%$ não responderam. Neste quesito os usuários encontram-se totalmente insatisfeitos o que fica claro pela maioria não responder a esta questão.

Sobre as opções para alimentação disponível no aeroporto $37,7 \%$ deram nota 1 , $12,3 \%$ deram nota $2,16 \%$ deram nota $3,12,3 \%$ deram nota $4,0,9 \%$ deram nota $5,20,7 \%$ não responderam. Como já era de esperar na praça de alimentação há apenas um local que fornece alimentos e com uma opção bem restrita.

Questionados sobre se as poltronas para espera do embarque são confortáveis 2,8\% deram nota $1,13,2 \%$ deram nota $2,43,4 \%$ deram nota $3,25,5 \%$ deram nota $4,9,4 \%$ deram nota 5 e $5,7 \%$ não responderam. Os dados indicam que os clientes encontram-se parcialmente insatisfeitos com as poltronas.

Quanto a disponibilidade de taxis 2,8\% deram nota $1,26,4 \%$ deram nota $2,28,3 \%$ deram nota $3,20,8 \%$ deram nota $4,15,1 \%$ deram nota 5, e $6,6 \%$ não responderam. Neste quesito os usuários encontram-se parcialmente insatisfeitos e parcialmente satisfeito.

Sobre o transporte público disponível $22,6 \%$ deram nota $1,13,2 \%$ deram nota $2,5,7 \%$ deram nota 3, 0,9\% deram nota 4 e 5 e $56,6 \%$ não responderam. Os dados mostram que a maioria encontra-se insatisfeito com essa questão.

Por fim foi questionado sobre o nível de satisfação dos clientes quanto aos serviços prestados pela companhia e $21,7 \%$ encontram-se totalmente satisfeito; $68,9 \%$ encontram-se 
parcialmente satisfeito; 6,6\% encontram-se Indiferente e $2,8 \%$ não responderam. Os dados mostram que mesmo que os clientes se encontram insatisfeitos com alguns quesitos prestados pela companhia ou devido a estrutura aeroportuária a maioria encontra-se parcialmente satisfeito.

\section{DISCUSSÃO}

\section{Marketing}

Fidelizar e reter o seu cliente por um longo período têm sido o objetivo das prestadoras de serviços. Segundo Kotler, (2015, p.2) "Marketing é a gestão de relacionamentos lucrativos com o cliente". Quanto mais tempo o cliente permanecer fiel maior será a lucratividade de uma empresa. Ainda o mesmo autor (2015, p. 2) explica que "os dois principais objetivos do marketing são: atrair novos clientes, prometendo valor superior, e manter e cultivar os clientes atuais, entregando satisfação".

O marketing em si pode e deve ser utilizado como forma de atrair novos consumidores, mas manter e reter estes irá depender da qualidade da prestação de serviços da empresa, por isso sempre é necessário a implementação do marketing interno, treinando seus colaboradores para que os mesmos consigam fazer um marketing externo, que desempenha qualidade na visão dos consumidores do serviço.

Uma das mais valiosas habilidades que os profissionais de marketing pode ter é a capacidade de selecionar, instruir e reunir as pessoas dentro da organização, de modo que todos os funcionários participem com entusiasmo do marketing externo, a fim de construir relacionamentos de longo prazo lucrativos com os clientes. (KOTLER, 2005, p.16)

O marketing tem que ser aplicado de dentro para fora, os profissionais que trabalham têm que estar ciente do que a empresa busca, e trabalhar em função a isto, sempre mostrando entusiasmo para atender os clientes, mantendo assim os mesmos clientes na empresa, aumentando a lucratividade da companhia. Quando se pensa em buscar novos clientes, o marketing auxilia nessa busca, fazendo com que os clientes conheçam os produtos ou serviços prestados na organização, e quando o cliente vai ate a empresa, é importante que ele seja bem tratado, por isso o marketing precisa ser implementado primeiramente com os colaboradores, para que os mesmos saibam tratar seus clientes, buscando sempre que o cliente volte à empresa, e quando o cliente volta a organização e novamente é bem tratado isso vai gerando formas de fidelizar o cliente na organização, fator de importância para o marketing. Segundo Kotler (2014, p.6)

[...] Os clientes criam
expectativas com relação
ao valor e á satisfação de
varias ofertas e compram
de acordo com essas
expectativas. Os clientes
satisfeitos compram
novamente e comentam
com outras pessoas sobre
suas boas experiências. Já
os clientes insatisfeitos
geralmente migram para a
concorrência e depreciam
o produto para os outros
[...]

A organização tem que buscar satisfazer as expectativas dos clientes, buscando prestar serviços de qualidades, pois quando um cliente sai da organização satisfeito, ele faz um marketing positivo para a empresa, mais conhecido como marketing boca a boca, que é quando o cliente demonstra suas experiências com pessoas próximas, seja elas negativas ou não, já quando não é superado as suas expectativas ele sai insatisfeito realizando assim o marketing negativo, assim podendo afastar possíveis clientes que a empresa poderia conquistar. Quando isso acontece a empresa tem que buscar por intermédio de pesquisas detectar o que o cliente espera da companhia, assim buscando satisfazer as expectativas que os clientes têm referente aos serviços prestados.

\section{Marketing de Serviço}

Segundo Cobra (2014, p.81) "O objetivo do marketing é satisfazer necessidades e desejos dos consumidores por meio de produtos e serviços. E para tanto é preciso conhecer as pessoas, seus desejos, suas necessidades e até mesmo suas fantasias..."

Toda e qualquer organização que deseja ter sucesso precisa identificar as necessidades e os desejos do cliente para que assim use isso a 
seu favor, buscando estratégias para alcançar o maior número possível de novos consumidores.

A empresa pode buscar o marketing estratégico para utilizar melhor seus recursos e aumentar seu lucro, segundo Cobra (2014, p.47) "As ações estratégicas de marketing devem ser formuladas com o objetivo de maximizar os recursos alocados de maneira a gerar lucro".

A organização necessita utilizar de forma eficiente e eficaz os recursos que já possui, e no caso de uma companhia aérea é preciso que sejam utilizados os recursos de atendimento com qualidade.

Quando se fala em serviço, é necessário observar o comportamento do consumidor, desde quando ele efetua a compra do serviço, até após a realização do serviço, segundo Gianesi e Corrêa (2008, p. 72) "O comportamento do consumidor após a compra do serviço depende de seu grau de satisfação com o resultado. Quanto mais satisfeito com o serviço estiver o consumidor, maior será a probabilidade de repetição da compra". O fornecedor do serviço prestado, precisa buscar satisfazer as necessidades do cliente, sempre fazendo um atendimento que ele se sinta a vontade, bem orientado, e feliz com a forma que é tratado, buscando sempre retornar a empresa, e realizar novas compras.

"As necessidades pessoais dos clientes, contudo, é que são o principal fator formador de suas expectativas, já que é visando atender a estas necessidades que os clientes procuram um serviço". (GIANESI; CORRÊA, 2008, p.82, grifo do autor)

Os usuários dos serviços prestados pela empresa buscam atender suas necessidades, mas essas necessidades muitas vezes se transformam em desejos, o que influencia na sua decisão de compra, e a empresa tem que trabalhar em cima disso como um diferencial competitivo para conseguir além de suprir as necessidades também atender seus desejos e expectativas. Segundo os mesmos autores (2008, p.86) "A percepção que o cliente tem do serviço prestado é formada por dois fatores principais: a prestação do serviço e a comunicação transmitida ao cliente durante ou após o processo."

A prestação do serviço é um fator influenciador quanto a percepção do cliente, pois o mesmo busca que o serviço seja prestado de uma maneira com que o mesmo saia satisfeito, outro fator influenciador é a comunicação transmitida para o cliente durante a prestação do serviço, o que demonstra que o colaborador tem que prestar informações claras e concisas para o comprador, para que o mesmo se sinta confiante dentro da empresa, e que saia da mesma com a certeza de que sempre será bem atendido, e bem informado.

$\mathrm{Na}$ prestação de serviço alguns fatores são determinantes para a empresa tais como a confiabilidade, presteza, segurança, empatia e tangibilidade.

Quanto à confiabilidade refere-se "a habilidade de prestar serviço de forma confiável, precisa e consistente" (GIANESE E CORRÊA, 1994. p.90). Desta maneira segundo Gianesi e Corrêaa empresa deverá prestar um serviço de forma confiável, deixando seu cliente seguro de que tudo que foi prometido será cumprido, de forma clara, explicando todas as informações necessárias, sendo consistente, duradoura, deixando o usuário satisfeito fazendo com que o mesmo retorne a empresa.

Quanto a Presteza refere-se para "a disposição de prestar o serviço prontamente e auxiliar os clientes". (GIANESE; CORRÊA, 2005, p.90). A presteza é um dos fatores importantes na prestação de serviço, pois é o modo como o atendente (colaborador) irá tratar o nosso cliente, ele precisa atendê-los com disposição, boa vontade em ajudá-lo e auxiliá-lo no que for preciso.

Através de pesquisas pioneiras de Parasuramam, Zerithaml e Berry (2014) sobre a qualidade do serviço prestado foi constatado que os consumidores não notam os diferencias de forma ampla e sim avaliam conforme o que há relevância para o mesmo dentro de todo o contexto que ocorreu ou que irá ocorrer. E ainda sendo esses autores foram notadas cinco dimensões para a classificação dos Serviços, tendo entre elas:

A confiabilidade: Onde se é comprido o que foi prometido, tendo como definição a forma que se tem para conseguir mostrar aos seus consumidores o cumprimento 0 que foi permitido, de uma forma confiável, verídica e precisa, ou seja, a confiabilidade nada mais é do que a empresa conseguir cumprir com suas promessas divulgadas sobre a prestação do serviço prestado, pois os consumidores preferem se relacionar com empresas que cumpram com suas promessas e resolvam os problemas relacionados ao serviço prestado. (PARASURAMAM; ZERITHAML; BERRY, 2014). 
A responsividade: Disponibilidade de auxiliar, podendo se disser que é a Maneira que a empresa se dispõe a ajudar o cliente, a disposição de resolver problemas, tirar dúvidas ou até mesmo orientá-los, vendo o tempo que o cliente tem que esperar pelas respostas ou fornecimento de orientações, verificando se a empresa irá oferecer uma resolução e serviço de imediato.

Para conquistar a excelência no quesito responsividade, a empresa deve visualizar o processo que ocorre para atender a necessidade dos clientes pela visão externas de quem irá usufruir avaliando os processos internos e a maneira que o executa. $E$ tendo uma quantidade de colaboradores suficiente para atender nas posições à frente com responsabilidade para assim informar os consumidores da melhor maneira. (PARASURAMAM; ZERITHAML; BERRY, 2014)

A segurança: Podendo ser definido como o conhecimento e a cortesia dos colaboradores, a maneira como a empresa e seus funcionários consegue inspirar a confiança dos seus clientes, sendo muito importante para serviços que são ligados a segurança, pois se exige um conhecimento das pessoas que atendem e a confiança que irá ser transmitida pelas pessoas que estão há frente no atendimento, pois essas pessoas que fazem o elo entre consumidores e empresa como um atendente de Check-in, secretaria tem que estar segura e tendo certeza das informações fornecidas e as empresas buscam concretizar a confiança e fidelização por meios das pessoas que estão em contato com os consumidores. (PARASURAMAM; ZERITHAML; BERRY, 2014)

A empatia: Sendo definida como será o atendimento a cada cliente conforme suas necessidades. A empatia vai se caracterizar como tratar cada cliente conforme suas necessidades de maneiras personalizadas e que o cliente possa compreender, pois conforme a empresa vai crescendo vai diminuindo a quantidade de empatia devido o grande número de cliente e exigências, pois os consumidores exigem que a empresa tenha conhecimento de todos os seus setores. (PARASURAMAM; ZERITHAML; BERRY, 2014)

Os tangíveis: Definidos com as formas de comunicação e equipamentos e materiais físicos utilizados, que mostram a qualidade do serviço, podendo utilizar de uma forma estratégica, da maneira tangível e utilizando de outras formas como a limpeza do ambiente os alimentos servidos e até a uniformização das pessoas à volta. (PARASURAMAM; ZERITHAML; BERRY, 2014)

Nem sempre os consumidores dos serviços utilizam das cinco dimensões, pois podem notar a forma com que os clientes organizam as referências que obteve sobre a qualidade do serviço podendo se falar de um atendimento no balcão do check-in ou no ato de seu desembarque, tanto da forma que foi realizada o atendimento ou como estão as instalações local, sempre respeitando o contrato realizado com o cliente e respeitando os órgão que o fiscalizam, realizando de uma forma segura mantendo a credibilidade para que assim haja uma confiança entre a organização e os consumidor.

Manter-se competitivo no mercado tem sido uma das principais preocupações das empresas. Neste quesito as organizações procuram satisfazer os seus consumidores, no intuito de fideliza lós. Nas companhias aéreas não é diferente.

Assim, essa pesquisa teve como objetivo principal identificar e analisar a percepção dos usuários quanto ao serviço prestado pela companhia de transporte aéreo doméstico e ainda a estrutura aeroportuária da cidade de Presidente Prudente/SP.

Para alcançar o objetivo proposto 106 usuários responderam ao questionário sendo os mesmos de quatro horários diferentes, cinco horas e vinte minutos com destino a cidade de Campinas/SP, onze horas e quinze minutos com destino a cidade de Campinas, quatorze horas e cinco minutos com destino a cidade de Porto Seguro/BA e dezenove horas etrinta e cinco minutos com destino para Campinas. Para esta análise considerou-se notas estabelecidas entre 1 a 5 sendo que a nota cinco o usuário concordava totalmente e a nota um o usuário discordava totalmente.

Destaca-se na pesquisa que $54,7 \%$ escolhem a companhia aérea por ter o menor preço quando comparada com a concorrente e $24,5 \%$ pelo atendimento prestado. Neste caso a empresa deverá fidelizar os seus usuários não somente pelo preço, mas sim pelo atendimento, - que leva a melhorar ainda mais o seu atendimento em comparação com a concorrente.

Visto que a maioria dos usuários compram suas passagens aéreas utilizando o site da empresa ou o aplicativo de celular a empresa 
deve investir ainda mais nestas ferramentas. A tendência é aumentar o uso das mesmas.

Uma das hipóteses dos pesquisadores era de que os usuários se encontravam satisfeitos com o serviço prestado pela companhia o que provou ser verdadeiro conforme demonstra a tabela abaixo. Nota-se que $32,61 \%$ dos usuários deram nota 5 e $36,7 \%$ deram nota 4 o que significa que se encontram totalmente e parcialmente satisfeitos. Destaca-se que no quesito funcionários os usuários atribuíram maiores notas, sendo uma média de 38,68\% e $40,56 \%$ entre totalmente e parcialmente satisfeitos.

Tabela 1 - Nível de satisfação da companhia aérea

\begin{tabular}{|c|c|c|c|c|c|c|c|}
\hline & \multirow[b]{2}{*}{ Itens avaliados } & \multicolumn{6}{|c|}{ Notas estabelecidas } \\
\hline & & 5 & 4 & 3 & 2 & 1 & $N / R$ \\
\hline \multicolumn{2}{|r|}{ GERAIS } & $\%$ & $\%$ & $\%$ & $\%$ & $\%$ & $\%$ \\
\hline 1 & $\begin{array}{l}\text { No site é fácil encontrar o que } \\
\text { necessito }\end{array}$ & 30,2 & 52,8 & 13,2 & 1,9 & 0,0 & 1,9 \\
\hline 2 & $\begin{array}{l}\text { O site facilita a navegação por } \\
\text { onde eu quero }\end{array}$ & 26,4 & 45,3 & 23,6 & 2,8 & 0,0 & 1,9 \\
\hline 3 & $\begin{array}{l}\text { O site facilita completar a } \\
\text { transação rapidamente }\end{array}$ & 26,4 & 45,3 & 23,6 & 2,8 & 0,0 & 1,9 \\
\hline 4 & $\begin{array}{l}\text { As informações no site são bem } \\
\text { organizadas }\end{array}$ & 20,8 & 45,3 & 27,4 & 4,7 & 0,9 & 0,9 \\
\hline 5 & $\begin{array}{l}\text { As páginas no site carregam } \\
\text { rapidamente }\end{array}$ & 26,4 & 3,33 & 33 & 5,7 & 0,9 & 0,9 \\
\hline 6 & $\begin{array}{l}\text { O site auxilia o usuário a navegar } \\
\text { dentro dele de modo rápido }\end{array}$ & 27,4 & 38,7 & 21,7 & 9,4 & 0,9 & 1,9 \\
\hline 7 & O site está sempre disponível & 27,4 & 41,5 & 22,6 & 7,5 & 0,0 & 0,9 \\
\hline 8 & $\begin{array}{l}\text { Emissão do cartão de embarque } \\
\text { pelo aplicativo }\end{array}$ & 28,1 & 32,1 & 32,1 & 2,8 & 0,9 & 3,8 \\
\hline 9 & $\begin{array}{l}\text { Horários de serviços extras (ônibus, } \\
\text { parceiras) }\end{array}$ & 33 & 43,4 & 16 & 3,8 & 0,0 & 3,8 \\
\hline 10 & Programa de fidelidade & 36,8 & 35,8 & 15,1 & 3,8 & 2,8 & 5,7 \\
\hline 11 & Valores de excesso de bagagem & 11,3 & 19,8 & 34 & 21,7 & 7,5 & 5,7 \\
\hline 12 & Valores de alteração & 8,5 & 15 & 36,8 & 29,2 & 6,6 & 3,7 \\
\hline 13 & Chat para tirar dúvidas & 26,4 & 36,8 & 29,2 & 2,8 & 0,0 & 4,7 \\
\hline 14 & Cancelamento de passagem & 14,2 & 26,4 & 41,5 & 13,2 & 0,9 & 3,7 \\
\hline \multicolumn{2}{|r|}{ Total } & 343,3 & 481,53 & 369,8 & 112,1 & 21,4 & 41,4 \\
\hline \multicolumn{2}{|r|}{ Média } & 24,5 & 34 & 26 & 8 & 1,5 & 3 \\
\hline \multicolumn{8}{|c|}{ QUANTO AOS FUNCIONÁRIOS } \\
\hline 1 & Boa aparência dos funcionários & 48,1 & 37,7 & 11,3 & 0,9 & 0,0 & 1,9 \\
\hline 2 & Cortesia dos funcionários & 33 & 43,4 & 21,7 & 0,0 & 0,0 & 1,9 \\
\hline 3 & $\begin{array}{l}\text { Boa vontade dos funcionários para } \\
\text { lidar com problemas inesperados }\end{array}$ & 34 & 43,4 & 18,9 & 1,9 & 0,0 & 1,9 \\
\hline 4 & $\begin{array}{l}\text { Rapidez na solução de problemas e } \\
\text { esclarecimento de dúvidas }\end{array}$ & 30,2 & 40,6 & 24,5 & 1,9 & 0,0 & 2,8 \\
\hline 5 & $\begin{array}{l}\text { Soluções e esclarecimentos de } \\
\text { dúvidas vias telefone }\end{array}$ & 48,1 & 37,7 & 8,5 & 0,9 & 0,0 & 4,7 \\
\hline & Total & 193,4 & 202,8 & 84,9 & 5,6 & 0 & 13,2 \\
\hline & Média & 38,68 & 40,56 & 16,98 & 1,12 & 0 & 2,64 \\
\hline \multicolumn{8}{|c|}{ QUANTO AS AERONAVES/SERVIÇOS } \\
\hline 1 & Tem aparência moderna & 48,1 & 37,7 & 8,5 & 0,9 & 0,0 & 4,7 \\
\hline 2 & $\begin{array}{l}\text { Atendimento das comissárias nos } \\
\text { voos }\end{array}$ & 47,2 & 38,7 & 10,4 & 0,0 & 0,0 & 3,8 \\
\hline
\end{tabular}




\begin{tabular}{|c|c|c|c|c|c|c|c|}
\hline 3 & Alimentação dentro das aeronaves & 34,9 & 35,8 & 15,1 & 11,3 & 0,0 & 2,8 \\
\hline 4 & $\begin{array}{l}\text { Informações do voo por parte do } \\
\text { piloto }\end{array}$ & 42,5 & 36,8 & 17,9 & 0,0 & 0,0 & 2,8 \\
\hline 5 & $\begin{array}{l}\text { Rapidez no embarque e } \\
\text { desembarque }\end{array}$ & 40,6 & 41,5 & 13,2 & 1,9 & 0,0 & 2,8 \\
\hline 6 & Cumpre os horários fornecidos & 45,3 & 36,8 & 13,2 & 1,9 & 0,0 & 2,8 \\
\hline 7 & Estão sempre limpas & 47,2 & 39,6 & 9,4 & 0,9 & 0,0 & 2,8 \\
\hline 8 & Os assentos são confortáveis & 35,8 & 49,1 & 9,4 & 2,8 & 0,0 & 2,8 \\
\hline 9 & Tempo de conexão & 34,9 & 34 & 19,8 & 7,5 & 0,9 & 2,8 \\
\hline & Total & 376,5 & 350 & 116,9 & 27,2 & 0,9 & 28,1 \\
\hline & Média & 41,8 & 38,9 & 13 & & 0,1 & 3, \\
\hline & Total Geral & 913,2 & 1034,3 & 571,6 & 144,9 & 22,3 & 82,7 \\
\hline & Média Geral & 32,61 & 36,7 & 20,4 & 5,1 & 0,79 & 2,93 \\
\hline
\end{tabular}

Fonte: Elaborado pelos próprios autores

A segunda hipótese dos pesquisadores era de que os usuários procuravam melhoria na estrutura portuária o que também se julgou verdadeira conforme pode-se verificar no quadro abaixo. $30,5 \%$ deram nota 3 e $20,4 \%$ deram nota
2 o que demonstra que estão insatisfeitos. Outro dado que chama a atenção é a quantidade de pessoas que não responderam o que leva a concluir que estão muito insatisfeitos.

Tabela 2 - Nível de satisfação da estrutura aeroportuária

\begin{tabular}{|c|c|c|c|c|c|c|c|}
\hline \multirow{2}{*}{\multicolumn{2}{|c|}{ Itens avaliados }} & \multicolumn{6}{|c|}{ Notas estabelecidas } \\
\hline & & 5 & 4 & 3 & 2 & 1 & $N / R$ \\
\hline 1 & Fácil localização & 8,5 & 25,5 & 39,6 & 20,8 & 3,8 & 0,0 \\
\hline 2 & Valor do estacionamento & 3,8 & 9,4 & 45,3 & 36,8 & 0,9 & 3,8 \\
\hline 3 & Banheiros & 2,8 & 17,9 & 18,9 & 44,7 & 5,7 & 10,4 \\
\hline 4 & Praça de alimentação & 2,8 & 8,5 & 16 & 19,8 & 43,4 & 9,4 \\
\hline 5 & Placas indicativas & 4,7 & 17,9 & 34 & 30,2 & 6,6 & 12,3 \\
\hline 6 & Informações em geral & 9,4 & 22,6 & 42,5 & 20,8 & 1,9 & 2,8 \\
\hline 7 & Balcões da empresa & 11,3 & 40,6 & 38,7 & 5,7 & 0,9 & 2,8 \\
\hline 8 & Sala de embarque & 15,1 & 35,8 & 32,1 & 13,2 & 1,9 & 2,8 \\
\hline 9 & Ambiente agradável & 6,6 & 32,1 & 42,5 & 13,2 & 2,8 & 3,7 \\
\hline 10 & WI-FI & 0,0 & 0,0 & 0,9 & 1,9 & 4,7 & 90,5 \\
\hline 11 & Opções para alimentação & 0,9 & 12,3 & 16 & 12,3 & 37,7 & 20,7 \\
\hline 12 & $\begin{array}{l}\text { Poltronas confortáveis na espera do } \\
\text { embarque }\end{array}$ & 9,4 & 25,5 & 43,4 & 13,2 & 2,8 & 5,7 \\
\hline 13 & Taxis disponíveis & 15,1 & 20,8 & 28,3 & 26,4 & 2,8 & 6,6 \\
\hline 14 & Transporte público disponível & 15,1 & 20,8 & 28,3 & 26,4 & 2,8 & 6,6 \\
\hline & Total & 105,5 & 105,5 & 426,5 & 285,4 & 118,7 & 178,1 \\
\hline & Média & 7,5 & 7,5 & 30,5 & 20,4 & 8,5 & 12,7 \\
\hline
\end{tabular}

Fonte: Elaborado pelos próprios autores

Quanto a estrutura aeroportuária as companhias aéreas não têm condições de melhorar visto que a mesma é gerida por um órgão independente, mas nota-se que uma estrutura deficitária influencia na percepção dos usuários visto que os mesmos não conseguem separar a estrutura aeroportuária dos serviços prestados pela companhia.

Para se manter ou aumentar a sua competitividade perante a sua concorrente a companhia aérea em questão precisa analisar os itens que demonstram que os usuários estão menos satisfeitos e estabelecer estratégias de forma a aumentar a satisfação de seus usuários.

Sugere-se para novas pesquisas que seja realizada uma pesquisa com a empresa concorrente a fim de detectar os motivos que levam os demais indivíduos a utilizarem os serviços aéreos da empresa da mesma e não da empresa objeto da pesquisa.

\section{REFERÊNCIAS}


ANAC. Disponível

em: <http://www.anac.gov.br/assuntos/passagei ros>. Acesso em: 15 set. 2016.

AZUL LINHAS AÉREA. Disponível

em: <http://www.voeazul.com.br/sobre-azul>.

Acesso em: 31 out. 2016.

COBRA, M. Administração de marketing no

Brasil. 3. ed. São Paulo: Elsevier, 2014.

GIANESI, I.G.N.; CORRÊA, H.L. Administração estratégica de serviços: operações para satisfação do cliente. São Paulo: Atlas, 1994.

GIANESI, I. G. N.; CORRÊA, H. L. Administração estratégica de serviços: operações para satisfação do cliente. São Paulo: Atlas, 2010.

KOTLER, P. Princípios de marketing. 15. ed. São Paulo: Person, 2014.

KOTLER, P. Marketing essencial. 2. ed. São Paulo: Person, 2005

LAKATOS, M.A; e E.V. Fundamentos de metodologia científica. 6.ed. São Paulo: Atlas, 2005.

MANZO, A. J. Manual para la preparación de monografia: una guía para presentar informes y tesis. Buenos Aires: Humanista, 1971.

ZEITHAMAL, V. A.; BITNER, M. J; GREMLER, D D. Marketing de serviços, a empresa com foco no cliente. 6. ed. Porto Alegre: Amgh, 2014.

Recebido para publicação em 07/08/2017

Revisado em 11/08/2017

Aceito em 21/08/2017 